Eighth Meeting, June 9, 1893.

Jonn Alison, Esq., M.A., F.R.S.E., President, in the Chair.

\title{
Japanese Arithmetic.
}

By Prof. C. G. KNotr, D.Sc., F.R.S.E.

The paper was mainly an account of the abacus, as used in China and Japan. The instrument was shown, and the various operations of addition, subtraction, multiplication, division, and extraction of square and cube roots, were illustrated. The multiplication and division tables were fully described, the latter being especially interesting. The historic development of the abacus in the East was also touched upon. A full account of the Chinese and Japanese abacus will be found in a paper by the author, entitled, "The Abacus, in its Historic and Scientific Aspects," published in the Transactions of the Asiatic Society of Japan (vol. XIV., 1886). A copy of this paper is in the library of the Edinburgh Mathematical Society.

\section{Revue Semestrielle des Publications Mathématiques:}

Rédigée sous les Auspices de la Société Mathématique d'Amsterdam.

Tome I. (Première Partie) : Amsterdam, W. Versluys, 1893, pp. 104.

The appearance of this Review is a significant indication of the enormous development of mathematical studies in recent years. Nearly every one who has attempted to keep himself abreast of mathematical research has been obliged sooner or later to recognise the practical impossibility of mastering the literature of every branch, and has resigned himself to a comparatively elementary study of the general subject while devoting his main energies to 
special departments. Even then, so numerous are the Societies that publish Proceedings and Transaciions, and so varied are the Journals that are chiefly mathematical in their content, that it is no easy matter for the mathematician to get a knowledge of what is being done in any special field by workers outside (sometimes in) his own country. The need for a publication that will, without undue delay, furnish a conspectus of the literature of the subject is thus a very real one. That the need has been felt is sufficiently shown by the synopses of the contents of other Journals, given in such publications as Darboux's Bulletin, and more especially by the excellent Jalurbuch über die Fortschritte der Mathematik. The last completed issue of the Jahrbuch, that for 1889, extends to upwards of 1300 pages, while that for 1890 , two parts of which have appeared, will evidently be as large. It is almost inevitable that a work of this magnitude should be a little late in appearing, and it is possibly in view of this fact that the Mathematical Society of Amsterdam lay stress on their intention to issue their notices of the various Journals "without any delay of importance" The first part of the first volume, a copy of which has been sent to our Society, contains a statement of the principles on which the Review is to be conducted, and it may be of interest to the members of the Society to have these presented in outline.

The object of the Review is to facilitate the study of the mathematical sciences by making known, without any delay of importance, the title and the principal contents of the mathematical memoirs published in the principal scientific Journals, and it is issued under the editorship of Messrs Schoute, Korteweg, Kapteyn, Kluyver, and Zeeman, who are assisted by a pretty large staff of contributors. In general, notices are to be given of memoirs on pure mathematics and mechanics, including hydrodynamics and the theory of elasticity, but excluding applied mechanies, mathematical physics, and astronomy. This selection seems to me a somewhat arbitrary one, but it may perhaps prove better in practice than the statement of it would suggest, since it is proposed to give the titles and the classification of memoirs on excluded subjects when these appear in Journals which are almost exclusively mathematical. All the same, it is not easy to understand why the line should be drawn at the theory of elasticity, which certainly offers no problems of greater mathematical interest than, 
for example, does the mathematical theory of electricity or even that of the conduction of heat.

As regards the notices of the memoirs the guiding principle is the following:- The title of the memoir will be preceded by one or more letters (notations) in accordance with the system of classification adopted by the International Congress on the Bibliography of the Mathematical Sciences; this will be followed by a very short abstract of the contents of the memoir, but in cases where the title and the letters of classification indicate sufficiently the contents of the paper no abstract will be added. The use of symbols of classification has many advantages and in large numbers of instances gives about as much information as a short abstract would do. Any one who has had experience in summarising mathematical papers knows the extreme difficulty, one might say the impossibility, of compressing into a few lines the substance of a really good article, and it is quite clear that in several instances the writers of the abstracts have felt themselves cramped in dealing with the important memoirs. The value of the Review, it seems to me, will be chiefly in the exhaustive list of titles of papers and in the system of classification adopted; the abstracts are in many instances admirably done, but even then do not furnish very much more information than the title and classification convey.

If the Society succeed in their intention of publishing the two parts which make up the annual volume at the times they propose, the Review should have a useful career before it; these are to appear on the first of January and the first of July respectively. The first part will contain an analysis of all works published between first March and first October of the preceding year, while the second will deal with those published between the latter date and the first March of the current year. It should be possible, I think, to keep to the dates proposed; any postponement would probably prove fatal to the success of the venture.*

It would seem that notices of text-books and independent works do not come within the scope of the Review. It would, I think, be

* I note, with plessure, that the Second Part of Vol. I. has appeared at the promised date, 
a valuable addition to have even the titles of the more inportant mathematical books that are annually published; they are often a considerable time in making their way outside the country that produces them.

The Review should prove very useful to all engaged in mathematical work. To every mathematician-and does any one deserve the name of mathematician who does not spend some portion of his leisure in reading original memoirs-this Review makes its appeal.

Georgr A. Gibson. 